\title{
Reconfigurable Radio Access Unit for DWDM to W-Band Wireless Conversion
}

Chorchos, ukasz; Rommel, Simon; Turkiewicz, Jarosaw P.; Tafur Monroy, Idelfonso ; Vegas OImos, Juan José

Published in:

IEEE Photonics Technology Letters

Link to article, DOI:

10.1109/LPT.2017.2656894

Publication date:

2017

Document Version

Peer reviewed version

Link back to DTU Orbit

Citation (APA):

Chorchos, ., Rommel, S., Turkiewicz, J. P., Tafur Monroy, I., \& Vegas Olmos, J. J. (2017). Reconfigurable Radio Access Unit for DWDM to W-Band Wireless Conversion. IEEE Photonics Technology Letters, 29(6), 489-492. https://doi.org/10.1109/LPT.2017.2656894

\section{General rights}

Copyright and moral rights for the publications made accessible in the public portal are retained by the authors and/or other copyright owners and it is a condition of accessing publications that users recognise and abide by the legal requirements associated with these rights.

- Users may download and print one copy of any publication from the public portal for the purpose of private study or research.

- You may not further distribute the material or use it for any profit-making activity or commercial gain

- You may freely distribute the URL identifying the publication in the public portal 


\title{
Reconfigurable radio access unit for DWDM to W-band wireless conversion
}

\author{
Chorchos, L.; Rommel, S.; Turkiewicz, J.P.; Tafur Monroy, I.; Vegas Olmos, Juan José \\ Published in: \\ IEEE Photonics Technology Letters
}

DOI:

10.1109/LPT.2017.2656894

Published: 15/03/2017

Document Version

Accepted manuscript including changes made at the peer-review stage

Please check the document version of this publication:

- A submitted manuscript is the author's version of the article upon submission and before peer-review. There can be important differences between the submitted version and the official published version of record. People interested in the research are advised to contact the author for the final version of the publication, or visit the DOI to the publisher's website.

- The final author version and the galley proof are versions of the publication after peer review.

- The final published version features the final layout of the paper including the volume, issue and page numbers.

Link to publication

Citation for published version (APA):

Chorchos, L., Rommel, S., Turkiewicz, J. P., Tafur Monroy, I., \& Vegas Olmos, J. J. (2017). Reconfigurable radio access unit for DWDM to W-band wireless conversion. IEEE Photonics Technology Letters, 29(6), 489-492. DOI: 10.1109/LPT.2017.2656894

\section{General rights}

Copyright and moral rights for the publications made accessible in the public portal are retained by the authors and/or other copyright owners and it is a condition of accessing publications that users recognise and abide by the legal requirements associated with these rights.

- Users may download and print one copy of any publication from the public portal for the purpose of private study or research.

- You may not further distribute the material or use it for any profit-making activity or commercial gain

- You may freely distribute the URL identifying the publication in the public portal ? 


\title{
Reconfigurable Radio Access Unit for DWDM to W-Band Wireless Conversion
}

\author{
Łukasz Chorchos, Student Member, IEEE, Simon Rommel, Student Member, IEEE, \\ Jarosław P. Turkiewicz, Senior Member, IEEE, Idelfonso Tafur Monroy, Senior Member, IEEE, and \\ Juan José Vegas Olmos, Senior Member, IEEE
}

\begin{abstract}
In this letter a reconfigurable Remote Access Unit (RAU) is proposed and demonstrated, interfacing dense wavelength division multiplexed (DWDM) optical and W-band wireless links. The RAU is composed of a tunable local oscillator, a narrow optical filter and a control unit, making it reconfigurable via software. The RAU allows selection of a DWDM channel and tuning of the radio carrier frequency. Real-time transmission results at $2.5 \mathrm{Gbit} / \mathrm{s}$ and performance measurements with offline data processing at 4 and $5 \mathrm{Gbit} / \mathrm{s}$ are presented. Error free real-time transmission was achieved after $15 \mathrm{~km}$ of standard single mode fiber and $50 \mathrm{~m}$ of wireless transmission with carriers between 75 and $95 \mathrm{GHz}$.
\end{abstract}

Index Terms-Radio-over-fiber, millimeter-wave communications, W-band wireless, real-time systems.

\section{INTRODUCTION}

G ROWING demand for high speed wireless data transmission increases year to year mostly due to the emerging end user demand for wireless services like 4K/Ultra High Definition TV or mobile gaming [1]. The new 5G mobile standard will meet those requirements partially by the use of higher radio frequencies from the millimeter wave $(\mathrm{mm}$ wave) range [2], [3]. Operation at these frequencies- from $30 \mathrm{GHz}$ to $300 \mathrm{GHz}$ - allows the use of wider transmission channels and clearly opens a possibility for significantly higher bit rates. Furthermore, regulations for the use of mm-waves allow lightly licensed or unlicensed link establishment. Nevertheless, signal generation in the mm-wave frequency range with traditional oscillators is complex.

To overcome this problem the use of optical heterodyne signal upconversion was proposed [4] and in recent years has attracted interest of many researchers [5]-[8] and even joint projects were established in this field. Those projects aim to provide feasible solutions, integrating present and future optical networks with wireless communications by utilizing photonic techniques. The Integrated Photonic Broadband Radio Access Units for Next Generation Optical Access Networks (IPHOBAC-NG) project is one thereof and aims to provide seamlessly integrable photonic solutions for wireless communications and to adapt them into currently existing wavelength

Manuscript received September 16, 2016; accepted January 20, 2017. This work was partly funded by the DFF FTP mmW-SPRAWL and EC IPHOBACNG (grant No. 619870) projects.

Ł. Chorchos and J. P. Turkiewicz are with the Institute of Telecommunications, Warsaw University of Technology, 00-665 Warsaw, Poland, e-mail: (lukaszchorchos@gmail.com).

S. Rommel, J. J. Vegas Olmos, and I. Tafur Monroy are with the Department of Photonics Engineering, Technical University of Denmark, $2800 \mathrm{Kgs}$. Lyngby, Denmark, e-mail: (sirem@fotonik.dtu.dk). division multiplexed passive optical networks (WDM-PONs) and even ultra dense wavelength division multiplexed PONs. The project targets to provide a complementary broadband access with speeds between $1-10 \mathrm{Gbit} / \mathrm{s}$ and a mobile backhaul with the speed of $3 \mathrm{Gbit} / \mathrm{s}$. To fulfill these requirements the IPHOBAC-NG project assumes the development of a new photonic RAU which will support reconfiguration of the optical channel allocation, which will not have an impact on the digital signal processing in the optical network unit (ONU) and optical network terminal (ONT), and will be energy efficient, fully integrated and compact. The proposed IPHOBAC-NG heterogeneous network architecture is presented in Fig. 1.

In this letter a reconfigurable Remote Access Unit (RAU) is proposed and demonstrated, interfacing DWDM optical and W-band wireless links to enable the IPHOBAC-NG network architecture. The proposed RAU utilizes optical heterodyne signal upconversion [9] for mm-wave wireless signal generation. The proposed RAU is composed of a reconfigurable optical filter for DWDM channel selection, a reconfigurable optical reference signal source, a photodiode and a control unit; section II provides a full description. Section III describes measurement setup and procedure. In section IV bit error rate measurements after transmission over $15 \mathrm{~km}$ of fiber and a wireless distance of $50 \mathrm{~m}$ are shown for $2.5 \mathrm{Gbit} / \mathrm{s}$ real-time transmission and 4 and $5 \mathrm{Gbit} / \mathrm{s}$ transmission with offline data processing.

\section{Remote Access Unit Design}

The reconfigurable RAU proposed in this letter and presented in Fig. 1 assumes a $100 \mathrm{GHz}$ spaced, C-band DWDM input signal which is fed into a tunable, voltage-controlled, optical fiber Fabry-Perot filter, selecting the desired channel. The filter employed has $2.5 \mathrm{~dB}$ insertion losses, a $3 \mathrm{~dB}$ bandwidth of $15 \mathrm{GHz}$ and a $20 \mathrm{~dB}$ bandwidth of $125 \mathrm{GHz}$, allowing operation in $100 \mathrm{GHz}$ spaced DWDM systems. The filter is controlled through a digital analog converter (DAC), providing an adjustable output voltage range between $-18 \mathrm{~V}$ and $18 \mathrm{~V}$ with 16 bit resolution, ensuring finesse to select any DWDM channel and easily reaching the required $16 \mathrm{~V}$ range for filter tuning across the whole C-band.

The selected channel from the DWDM signal is fed into a $3 \mathrm{~dB}$ coupler where is combined with the reference signal from a local oscillator (LO, a tunable laser with $100 \mathrm{kHz}$ linewidth and fine frequency tuning). The polarization of the LO is controlled with a manual polarization controller, to align signal 


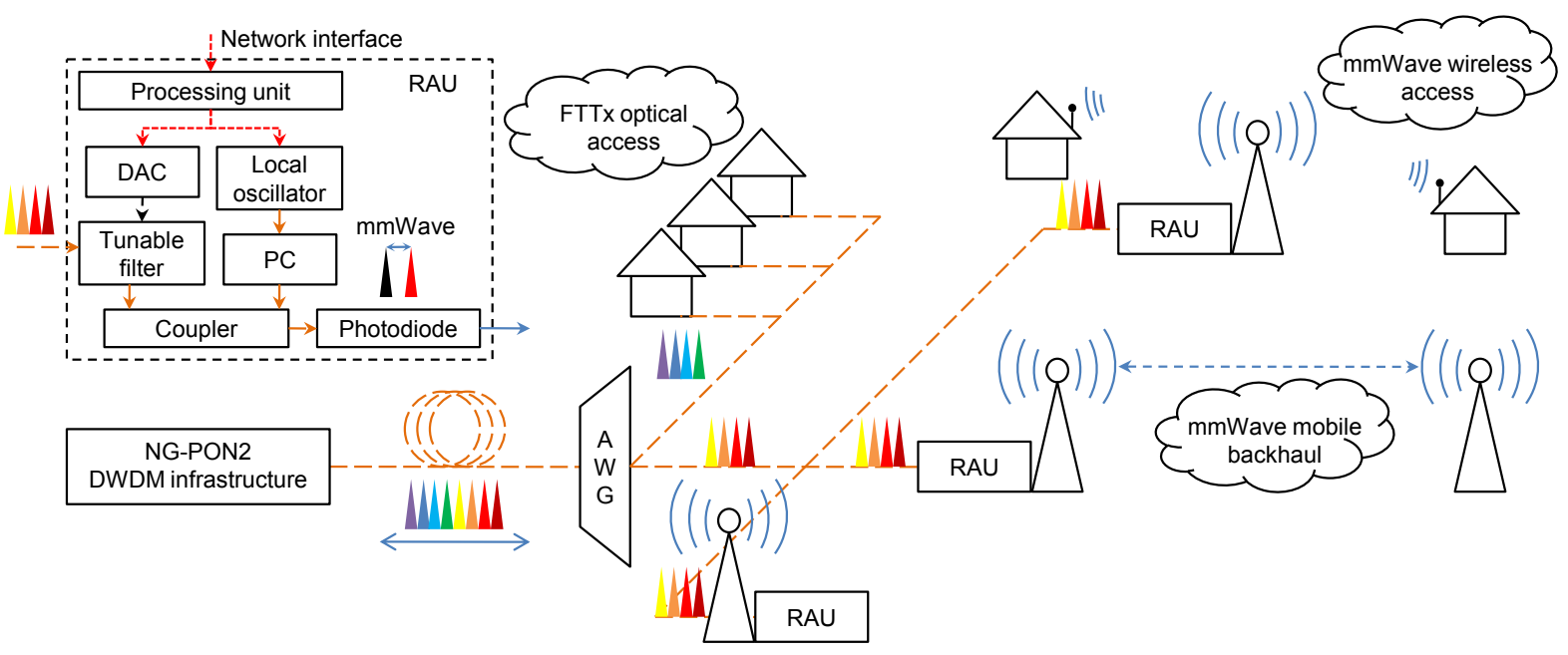

Fig. 1. IPHOBAC-NG architecture and block diagram of the proposed RAU, converting a DWDM optical signal to a W-band wireless signal.

and LO polarization and thus maximize beating efficiency on the photodiode. The addition of automatic LO polarization control - similar to eg. [10] - would alleviate need for manual intervention and allow a fully remote controlled RAU. The LO wavelength and DAC output are controlled by the processing unit, in the present case a low-cost Raspberry Pi 2 which can control a number of devices. Moreover, this single-board controller can be loaded with software-defined networking (SDN) extensions, effectively softwarizing the RAU.

The coupled data and reference signal, spaced according to the desired radio frequency, are sent to a photodiode (Finisar XPDV4120R) with $90 \mathrm{GHz} 3 \mathrm{~dB}$ bandwidth and a responsivity of $0.5 \mathrm{~A} / \mathrm{W}$. As a result of the heterodyning process at the photodiode, a radio signal with a carrier frequency in the $\mathrm{W}$ band range is generated. The total RAU optical insertion losses are $5.5 \mathrm{~dB} 2.5 \mathrm{~dB}$ from the optical filter and $3 \mathrm{~dB}$ from the coupler.

\section{Transmission Performance Measurements}

\section{A. Experimental Setup}

Fig. 2 depicts a block diagram of the experimental setup. Eight $100 \mathrm{GHz}$ spaced lasers were multiplexed in two $4 \times 1$ couplers with distinction for even and odd channels. Next, the two streams of four wavelengths each were fed into two MachZehnder modulators (MZM), preceded by two polarization controllers (PC). Both MZMwere biased at the center of their linear region and driven with two $2.5 \mathrm{Gbit} / \mathrm{s}$ (4 and $5 \mathrm{Gbit} / \mathrm{s}$ for offline data processing) non-return-to-zero (NRZ) pseudo random bit sequences (PRBS) with a length of $2^{11}-1$ bits from a pulse pattern generator. The sequence modulating the odd channels was negated and shifted with a delay line to impose signal decorrelation. The signals from MZMs were combined in a $3 \mathrm{~dB}$ coupler and transmitted through a combination of $10 \mathrm{~km}$ standard single mode fiber (SSMF) and $5 \mathrm{~km}$ of bend insensitive fiber (ITU-T G.657.B3) (BIF). This combination secures compatibility with deployment scenarios where BIF fiber is required to avoid large bending losses, while having little impact on the performance of the hybrid optical wireless system [11].

After the fiber, the DWDM signal was amplified with an erbium doped fiber amplifier (EDFA) to provide sufficient power for radio frequency (RF) signal generation and transmission. The EDFA was placed at the RAU rather than before fiber transmission, due to a limited output power of the available EDFA and thus insufficient power per channel if placed before fiber transmission. The use of an EDFA with an exemplary output power of $22 \mathrm{dBm}$ would allow EDFA placement in the central office (OLT) and yields a maximum fiber distance in the considered system configuration exceeding $20 \mathrm{~km}$ (assuming $13 \mathrm{dBm}$ per channel after the EDFA, $0.3 \mathrm{~dB} / \mathrm{km}$ fiber attenuation, $5.5 \mathrm{dBm}$ insertion losses of the RAU and a required power of $1 \mathrm{dBm}$ on the photodiode). The use of any EDFA might be avoided through the use of a semiconductor optical amplifier after the optical filter in the RAU.

After the EDFA the amplified signal is fed to the RAU. For each of the measured channels, polarization of the LO signal was adjusted to provide the maximum beating on the photodiode. The unused output of the coupler was used for signal monitoring with an optical spectrum analyzer (OSA). The output RF signal was transmitted over a distance of $50 \mathrm{~m}$ using a pair of parabolic W-band antennas with $48 \mathrm{dBi}$ gain each.

After $50 \mathrm{~m}$ of wireless transmission, the output of the receiver antenna was amplified and downconverted with a W-band Schottky diode envelope detector (ED) with a $3 \mathrm{~dB}$ bandwidth of $3 \mathrm{GHz}$. For the $2.5 \mathrm{Gbit} / \mathrm{s}$ real-time measurement two bias tees (BT) were cascaded, the first removing unwanted DC components from the envelope detector and the second providing the required $3.3 \mathrm{~V}$ DC for the clock and data recovery module (CDR). The output of the CDR was connected to a bit error rate tester (BERT) allowing direct bit error rate (BER) measurements. The receiver configuration for $4 \mathrm{Gbit} / \mathrm{s}$ and $5 \mathrm{Gbit} / \mathrm{s}$ transmission is analog to that described in [8]. 


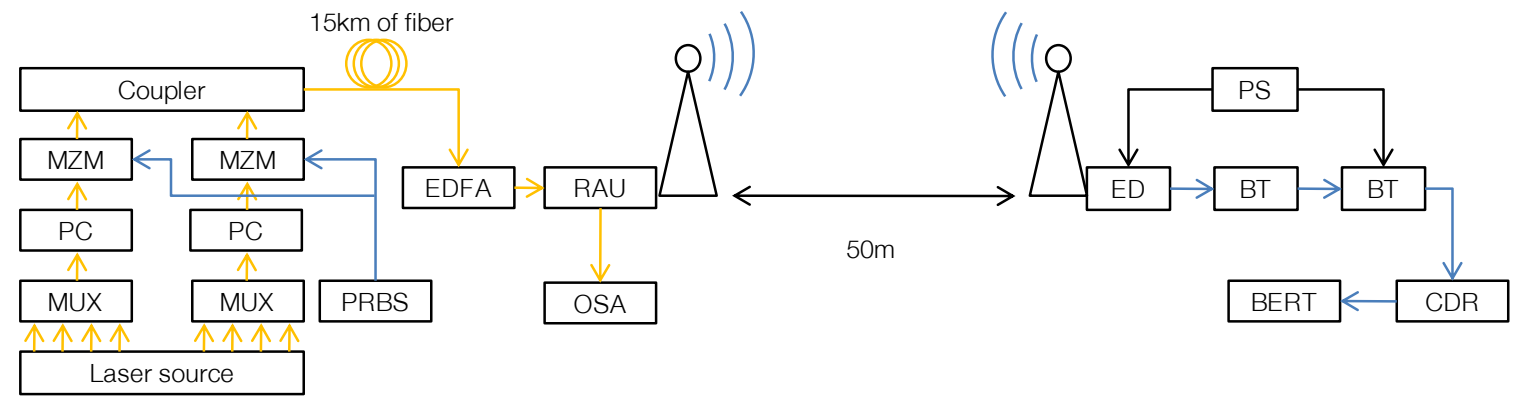

Fig. 2. Experimental setup for hybrid photonic $2.5 \mathrm{Gbit} / \mathrm{s}$ real time wireless transmission.

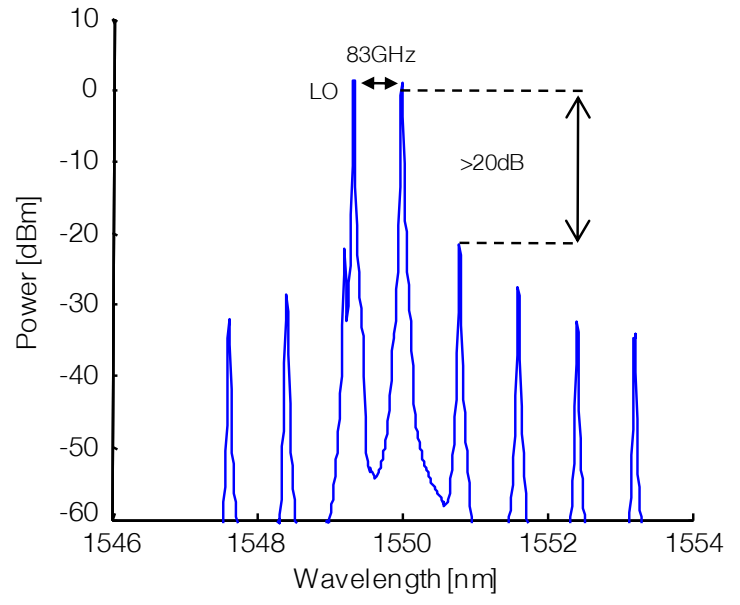

Fig. 3. Optical signal spectrum inside the RAU (after the coupler).

\section{B. Measurement Procedure}

The $2.5 \mathrm{Gbit} / \mathrm{s}$ real time and $4 \mathrm{Gbit} / \mathrm{s}$ with offline processing experiments were conducted for RF carrier frequencies between $75 \mathrm{GHz}$ and $95 \mathrm{GHz}$ with $2 \mathrm{GHz}$ steps. Those measurements were performed for $1^{\text {st }}, 5^{\text {th }}$ and $8^{\text {th }}$ DWDM channel. The $95 \mathrm{GHz}$ frequency upper bound was due to the operational bandwidth limit of the photodiode. The $5 \mathrm{Gbit} / \mathrm{s}$ experiment was performed for all DWDM channels at a frequency of $83 \mathrm{GHz}$. The decision to use W-band frequencies was made mainly due to lower attenuation in comparison to the $60 \mathrm{GHz}$ V-band which is also considered for 5G networks.

The measurements conditions were set through the control unit of the RAU, to which channel number and mm-wave frequency target were indicated. The control unit, through a look-up table, automatically set up the filter and LO. The LO was manually co-polarized with the signal and its power set level to the data channel to provide maximum generated $\mathrm{RF}$ signal power [7], [12]; the actual power was $1 \mathrm{dBm}$ each. Fig. 3 presents the optical spectrum for the $5^{\text {th }}$ DWDM channel inside the RAU after the filter and with the LO set $83 \mathrm{GHz}$ apart from the data channel. It can be clearly observed that adjacent DWDM channels are suppressed by over $20 \mathrm{~dB}$. For the real-time $2.5 \mathrm{Gbit} / \mathrm{s}$ transmission $5 \times 10^{10}$ bits were evaluated per measurement point. For the $4 \mathrm{Gbit} / \mathrm{s}$ and $5 \mathrm{Gbit} / \mathrm{s}$ measurements the number of analyzed buts was $>20 \mathrm{Mbit}$.

\section{RESULTS AND DisCUSSION}

Fig. 4 presents results for the $2.5 \mathrm{Gbit} / \mathrm{s}$ real-time measurement. Independent of the selected DWDM channel, similar BER characteristics were obtained. In the frequency range from $75 \mathrm{GHz}$ to $87 \mathrm{GHz}$ transmission with a BER below the limit of $3.8 \times 10^{-3}$ for a commercial forward error correction (FEC) with an overhead of $7 \%$ is possible for all tested channels. For carrier frequencies located close to $80 \mathrm{GHz}$ transmission considered as error free (BER $<10^{-9}$ ) can be achieved. It is worth to mention that this frequency range was designated for high-density fixed wireless services by the US Federal Communication Commission (FCC) and the RAU proposed in this letter can be easily utilized for this application.

For carriers above $87 \mathrm{GHz}$ an increase in the BER is visible, caused partially by the limited bandwidth of the photodiode and thus a lower conversion efficiency and second by interference from adjacent channels. Although adjacent channels are suppressed by more than $20 \mathrm{~dB}$, their remainders may beat with the selected channel, causing an RF component at $100 \mathrm{GHz}$, i.e. within W-band and thus within the transmission bandwidth of the antennas and the bandwidth of the receiver. Further impact may be taken from a loss of LO power due to beating with the closest adjacent channel. These are especially significant for the higher carrier frequencies and further explain the small advantage in BER observed for the outer channels where only one adjacent channel exists.

Fig. 5 shows the results obtained for the 4 and 5 Gbit/s transmission with offline data processing. At $4 \mathrm{Gbit} / \mathrm{s}$ transmission below FEC limit was achieved for frequencies up to $85 \mathrm{GHz}$. Above this frequency strong impact of the effects described above occur, especially for $5^{\text {th }}$ channel where the difference in BER at $87 \mathrm{GHz}$ between this channel and the $1^{\text {st }}$ is two orders of magnitude and compared to $8^{\text {th }}$ exceeds three orders of magnitude. Consequently the $5^{\text {th }}$ channel shows the worst performance among all channels. This relationship was further confirmed by the measurement at $5 \mathrm{Gbit} / \mathrm{s}$ and $83 \mathrm{GHz}$ where the $5^{\text {th }}$ channel also showed worst performance, close to the FEC limit. These results demonstrate that the middle channels are most affected by unwanted mixing products and loss of LO power even though the adjacent channels are attenuated more than $20 \mathrm{~dB}$. Never the less transmission of a $5 \mathrm{Gbit} / \mathrm{s}$ signal was successful for all channels on a $83 \mathrm{GHz}$ carrier.

It should be noted that the achieved maximum wireless distance of $50 \mathrm{~m}$ is limited only by the available RF power 


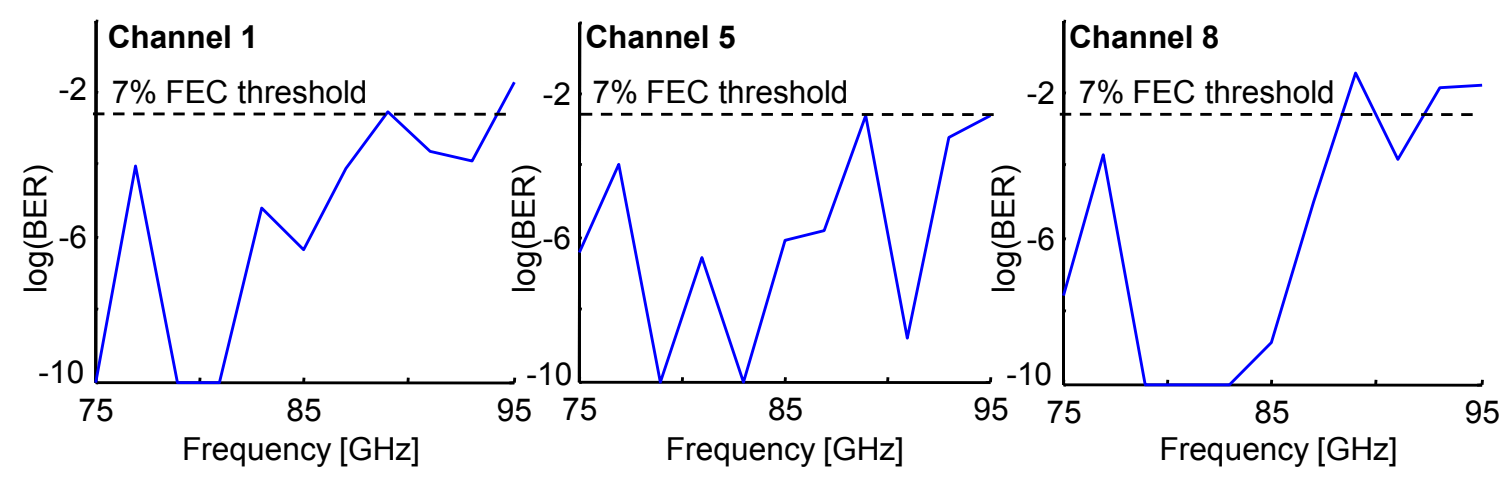

Fig. 4. BER measurement results obtained for $2.5 \mathrm{Gbit} / \mathrm{s}$ real time data transmission at frequencies ranging from 75 to $95 \mathrm{GHz}$ a) $1^{\text {st }}$ b) $5^{\text {th }}$ and c) $8^{\text {th }}$. DWDM channel
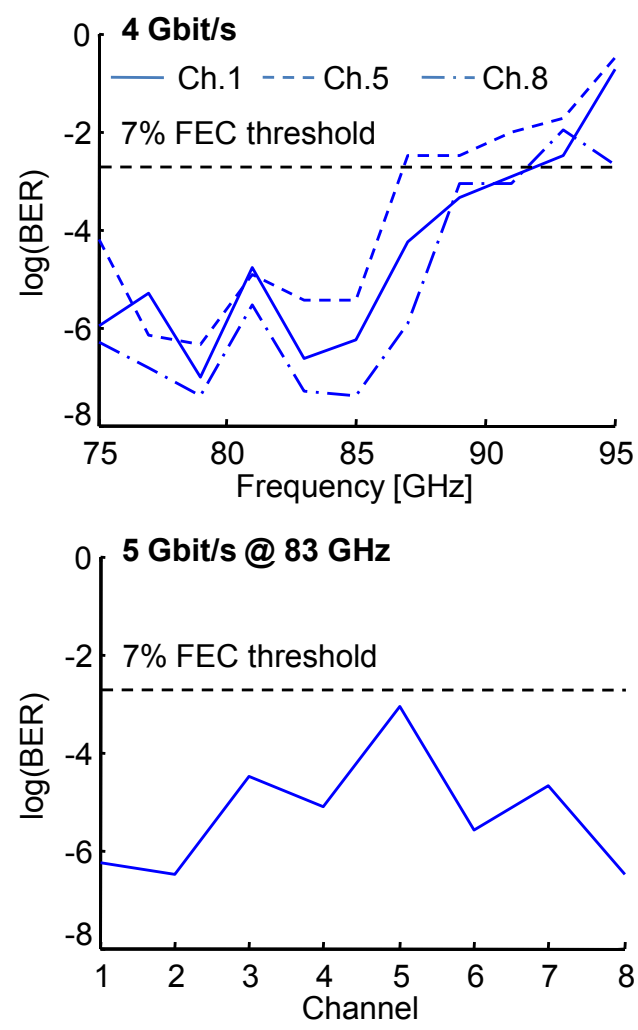

Fig. 5. Results of 4 and $5 \mathrm{Gbit} / \mathrm{s}$ tests with offline data processing

and significantly longer distance should be achievable as demonstrated in [8].

\section{Conclusions}

In this letter, a RAU utilizing optical heterodyne signal upconversion for generation and transmission of radio signals in millimeter-waves range was proposed and experimentally validated. The proposed RAU is widely reconfigurable allowing direct selection of the desired DWDM channel and gapless tuning of the local oscillator signal, allowing free selection of the radio carrier frequency in the W-band. Furthermore, the proposed RAU meets the requirements of the IPHOBAC-NG project, effectively and smoothly interfacing the optical and the wireless media. By allowing easy integration with existing PONs and by allowing extension of the control unit to support SDN it thus enables heterogeneous network architectures as envisioned in IPHOBAC-NG.

The performed measurements demonstrate error free $(\mathrm{BER}<$ $10^{-9}$ ) real-time transmission with a bitrate of $2.5 \mathrm{Gbit} / \mathrm{s}$ after $15 \mathrm{~km}$ of fiber and $50 \mathrm{~m}$ of wireless links. Transmission at data rates up to $5 \mathrm{Gbit} / \mathrm{s}$ is achieved with offline processing and a BER below the FEC limit. An increase in wireless distance ana$\log$ to [8] by increasing the RF power is possible, and therefore the wireless distance demonstrate in these experiments is not limited by any fundamental impairment.

\section{REFERENCES}

[1] P. Rost et al., "Cloud technologies for flexible 5G radio access networks," IEEE Commun. Mag., vol. 52, no. 5, pp. 68-76, 2014.

[2] T. S. Rappaport et al., "Millimeter wave mobile communications for 5G cellular: It will work!” IEEE Access, vol. 1, pp. 335-349, 2013.

[3] J. G. Andrews et al., "What will 5G be?" IEEE J. Sel. Areas Commun., vol. 32, no. 6, pp. 1065-1082, 2014.

[4] D. Wake, C. R. Lima, and P. A. Davies, "Optical generation of millimeter-wave signals for fiber-radio systems using a dual-mode DFB semiconductor laser," IEEE Trans. Microw. Theory Tech., vol. 43, no. 9, pp. 2270-2276, 1995.

[5] A. Hirata et al., "Transmission characteristics of 120-GHz-band wireless link using radio-on-fiber technologies," J. Lightwave Technol., vol. 26 , no. 15 , pp. 2338-2344, 2008.

[6] W.-J. Jiang et al., "40 Gb/s RoF signal transmission with $10 \mathrm{~m}$ wireless distance at $60 \mathrm{GHz}$," in Proc. OFC 2012. OSA, 2012, paper OTu2H.1.

[7] X. Pang et al., " 25 Gbit/s QPSK hybrid fiber-wireless transmission in the W-band $(75-110 \mathrm{GHz})$ with remote antenna unit for in-building wireless networks," IEEE Photon. J., vol. 4, no. 3, pp. 691-698, 2012.

[8] S. Rommel et al., "Outdoor W-band hybrid photonic wireless link based on an optical SFP+ module," IEEE Photon. Technol. Lett., vol. 28, no. 21, pp. 2303-2306, 2016.

[9] L. Deng et al., "42.13 Gbit/s 16QAM-OFDM photonics-wireless transmission in 75-110 GHz band," Progress In Electromagnetics Research, vol. 126, pp. 449-461, 2012.

[10] M. Yagi, S. Satomi, and S. Ryu, "Field trial of 160-Gbit/s polarizationdivision multiplexed RZ-DQPSK transmission system using automatic polarization control," in Proc. OFC 2008, 2008, p. OThT7.

[11] S. Rommel et al., "W-band photonic-wireless link with a Schottky diode envelope detector and bend insensitive fiber," Opt. Express, vol. 24, no. 11, pp. 11312-11322, 2016.

[12] X. Pang et al., "Centralized optical-frequency-comb-based RF carrier generator for DWDM fiber-wireless access systems," J. Opt. Commun. Netw., vol. 6, no. 1, pp. 1-7, 2014. 